Running head: RACISM, DISCRIMINATION, AND PREJUDICE

\title{
Racism, Discrimination, and Prejudice
}

\author{
Jillian Fish \\ Moin Syed \\ University of Minnesota
}

Version: May 7, 2020

This work is published:

Fish, J., \& Syed, M. (2020). Racism, discrimination, and prejudice. In S. Hupp \& J. Jewll (Eds.), Encyclopedia of Child and Adolescent Development. San Francisco: Wiley-Blackwell. 10.1002/9781119171492.wecad464

*Note: Earlier versions of this chapter were titled, "The Multiple Levels of Racism, Discrimination, and Prejudice."

Contact: fishx174@umn.edu 


\begin{abstract}
Within the psychological literature, there are numerous definitions of racism available. However, some fail to acknowledge concepts that are often bound up with racism, discrimination, and prejudice — such as power and privilege. In briefly discussing the history of race as a social construct, this entry seeks to understand the function that discrimination and prejudice serve in society. Additionally, shedding light on the process of racial formation provides context for the evolution of racism from overt and blatant to concealed and ambiguous, and embedded throughout society. In highlighting the various forms of racism, discrimination and prejudice, this entry provides an overview of adolescents' experiences with implicit, subtle, explicit, and institutional racism, and implications for their development and psychological well-being.
\end{abstract}

Keywords: Racism, discrimination, prejudice, adolescents. 


\section{The Multiple Levels of Racism, Discrimination, and Prejudice}

Before we can truly understand concepts such as discrimination and prejudice, we must first understand racism. In the present day, meanings of racism are wide and varied, making it difficult to grasp. When something so despicable and abhorrent— such as racism—is rendered obscure, it makes it nearly impossible for racism to be identified, acknowledged, and addressed. Consequently, when instances of racism are not blatant or overt (i.e., explicit) but rather are subconscious (i.e., implicit), covert in nature (i.e., subtle), and woven throughout the structure of society (i.e., institutional), the concept becomes increasingly difficult to understand. Consider the following example:

During his first week of attending a competitive, private high school, Hayes - $\mathrm{a}$ 13-year-old American Indian male_-is told by his peers, "Go back to the reservation!" Indeed, Hayes is the only American Indian student in the entire high school. When Hayes informs his teacher about this instance of explicit racism, she is astounded, then proceeds to apologize and empathizes. Seeing this as an opportunity to build a relationship with a new student, Hayes's teacher proceeds to ask, "If you don't live on the reservation, where do you live?" Upon hearing this, Hayes is confused - the high school he attends is located near a reservation; however, he lives in the town next to it. In fact, Hayes is not even affiliated with the tribe that is representative of the neighboring reservation. Hayes thinks his teacher means well, and shrugs the interaction off. Some weeks pass, and Hayes makes a friend whom he invites over on the weekend. However, to Hayes's disappointment, the friend cannot come over-ever-because his parents said no. 
Certainly, most — if not all—people will recognize the verbal assaults levied at Hayes by his fellow classmates as what is often called "old-fashioned racism." That is, Hayes's peers are forthright in communicating their biases and attitudes about American Indians to him. Indeed, the attitudes expressed toward Hayes are negative - rooted in the stereotype that all American Indians live on reservations. However, the remainder of the scenario is unclear. Hayes's teacher is obviously appalled at his peers' behavior, but seemingly endorses the same stereotype, as suggested by her question. Despite this, most people would be hard-pressed to label this as racism. Even less clear is the situation involving Hayes's new friend from school, whose parents prohibit their child from spending time with Hayes at his home. Again, this situation is vague and, consequently, difficult to understand and identify as racism. These are a few examples of racism embedded throughout the scenario, highlighted here to demonstrate the nuanced ways in which racism operates. This entry will return to this scenario with Hayes to gain a deeper understanding of the topic. First, it offers a review of the history of racism.

\section{Distinctions and Overlaps Between Racism, Discrimination, and Prejudice}

\section{Racism}

Traditionally, racism has been understood as negative and unfair treatment toward a particular group based on their ethnicity or race. Under this definition, racism is a two-way street, in which the roles of perpetrator and target are not mutually exclusive. In other words, people can be both perpetrators of racism and targets of racism.

Take, for example, affirmative action in US higher education — that is, policies that provide ethnic and racial minorities with academic and educational opportunities that have historically been denied to them. Though affirmative action is intended to make higher education accessible and equitable for ethnic and racial minorities, is not uncommon for White Americans 
to claim that such policies are discriminatory against White applicants. This phenomenon, which has been referred to as reverse racism or reverse discrimination, refers to the notion that ethnic and racial minorities are provided with opportunities at the expense of White people who are more qualified. With this example, we can see how a limited definition of racism that does not account for critical concepts, such as power and privilege, can enable and perpetuate inequities.

It is for these reasons that this traditional definition of racism can be considered rather limited, as it omits features that are essential to understanding racism, namely power and privilege (Cole, 2017). Thus, following the consensus in social science research, this entry defines racism as a system of power entwined with practices and beliefs that produce and maintain an ethnic and racial hierarchy. The preservation of this ethnic and racial hierarchy, in turn, leads to the superiority, power, and privilege of some, and the oppression of others. Under this definition, racism is a one-way street in which the role of the perpetrator is associated with those at the top of the ethnic and racial hierarchy, who are in positions of power and privilege (Cole, 2017). Consequently, those who occupy categories considered to be less superior on the ethnic and racial hierarchy fulfill the role of the target. According to this definition, the perpetrator engages in discrimination and prejudice as a means of reproducing and upholding the ethnic and racial hierarchy to the benefit of some at the detriment of others. Importantly, as elaborated below, this means that racism cannot be solely understood as a situational and interpersonal act. In this instance, if racism is a one-way street, discrimination and prejudice are the street signs and traffic lights that maintain the flow of traffic (i.e., the ethnic and racial hierarchy).

\section{Discrimination}

Discrimination refers to the unjust treatment of persons based on perceived, categorical 
differences, and thus is most accurately understood as an interpersonal act. Discrimination can be

positive or negative - that is, people can be treated better or worse based on their group

membership; however, research tends to focus on the latter. Indeed, when individuals are treated unjustly based on their group memberships, opportunities and options become limited, thereby, impacting quality of life. Additionally, discrimination can be verbal, including making threats or mocking others. However, it can also be physical, such as hitting, and relational, including excluding others. Moreover, discrimination occurs across various contexts. Indeed, discrimination is multifaceted. Whether it is positive or negative, physical or verbal, discrimination often stems from stereotypes and evaluations of particular groups of people.

\section{Prejudice}

On the other hand, prejudice refers to preconceived, unsubstantiated opinions of persons based on perceived categorical differences. Prejudice is thought to capture an individual's emotional response when interacting with or thinking about people who are affiliated with a different categorical group. Additionally, prejudice encompasses evaluations of a group — both positive and negative. These emotional responses to and evaluations of groups inform an individual's attitude directed toward people based on their group membership. It is important to note that research has demonstrated that one's evaluations of people and their perceived categorical group are a strong predictor of how one treats individuals from that group. Such evaluations are often automatic, resulting from an emotional reaction. Consequently, prejudice can-but does not always — occur outside one's consciousness.

Taken together, racism is a system of power that perpetuates ethnic and racial hierarchies, whereas discrimination corresponds to behaviors and prejudice corresponds to beliefs, both of 
which serve to support and reinforce racism as a system of power. In this way, racism serves as a foundational core from which we can understand discrimination and prejudice.

\section{Historical, Intellectual, and Social Context}

Despite the distinctions made above between racism, discrimination, and prejudice, they are all deeply intertwined, and forms of discrimination and prejudice play key roles in preserving the ethnic and racial hierarchy — a categorical structure that determines a given individual's or group's access to opportunities and benefits, among other things. It is important, then, to consider the long-standing history of race, as well as its origins.

The emergence of race as a concept can be dated as far back as the 16th century, when it was used as a general categorizing term - much akin to terms such as kind, type, or sort (Smedley \& Smedley, 2005). It was in the 17 th century that race eventually became a term to refer to the populations in North America at the time (i.e., Europeans, Africans, and American Indians) - the meaning of which was solidified in the 18th century, as it became customary to use race to denote social categories of these groups.

In addition to terminology, race also became an ideology, or set of beliefs. The beliefs surrounding race concerned human differences and a societal structure that corresponded to them. Certainly, the construction of a categorization system for humans was critical to the success of the Thirteen Colonies that eventually became the United States, the leaders of which designated African people as slaves. During a time that emphasized equality — that is, life, liberty, and the pursuit of happiness - it was imperative that a categorization system be established that would relegate African peoples to a less-than-human status. Consequently, African people were excluded from participation in society as anything other than slaves, whereas American Indians were deemed acceptable to be included under the condition that they 
were "civilized" — or, in other words, assimilated. Here, we can see the formation of an ethnic and racial hierarchy.

Beliefs about human differences and the use of racial categories have been bolstered through scientific research that posits that humans exhibit innate biological differences. First seen in the 19th and 20th centuries, research on racial biology suggested that populations differed in phenotype and genotype, and could be classified into discrete racial categories. Based on their classification, groups were deemed either superior or inferior. Examples of this can be seen in the work of monogenists Georges-Louis Leclerc and Johann Blumenbach (1795), who proposed classifications of race in which Caucasians were considered to be the original and superior race. More recently, Richard J. Herrnstein and Charles Murray (1994) suggested that genetics plays a role in the differences in IQ scores between races in The Bell Curve.

Although racial biology has been largely discredited in scientific communities, the belief that there are human differences — both physical and behavioral — between populations has prevailed. Consequently, race has endured as a concept and as an essential feature embedded into the fabric of society. This is true not only in the United States but also in most—if not allcountries around the world, including Brazil, China, France, and South Africa. This is due, in part, to the process of racialization. Racialization refers to the process of ascribing racial identities to a relationship or social practices (Miles, 1989). This often occurs as a part of domination, to enable sustained differential treatment, as people come to gradually adopt their ascribed identity. Take, for instance, the scenario with Hayes, who identifies as American Indian. Being American Indian in the United States has been imbued with poverty and desolate living conditions on reservations. This occurs through media coverage, representations in popular culture, and politics. Another example of this would be the ways in which poverty, crime, crack 
cocaine, and fatherlessness have been likened to Blackness. More recently, we have witnessed the global racialization of Muslims, conceptualized as terrorists bent on bringing down democracy and Western civilization more broadly.

Without a doubt, the ethnic and racial hierarchy that structures society is well established. Moreover, renewed interest in scientific classifications of humans - such as the sequencing of the human genome - has reified conceptualizations of humans as falling into discrete categories. Consequently, the persistent educational, health, and economic disparities faced by ethnic and racial minorities are attributed to racial differences, contributing to the racialization of these populations. Indeed, it is a self-sustaining, vicious cycle that benefits some to the detriment of others. As a means of transforming this ethnic and racial hierarchy to address persistent disparities, psychological researchers have homed in on discrimination and prejudice as an area of exploration.

\section{Research Trends}

Research on racism, discrimination, and prejudice in the social sciences can be traced back to the early 1930s. It was at this time that social psychologists Daniel Katz and Kenneth Braly (1933) studied the ethnic and racial stereotypes of undergraduate students at Princeton University. Their findings suggested that students attributed negative characteristics to particular ethnic and racial groups, despite not having contact with individuals from those groups. Additional research was conducted by Swedish economist Gunnar Myrdal (1944), the results of which were also groundbreaking. Myrdal (1944) found that White people used discrimination and prejudice to oppress Black people, which resulted in limited opportunities for Black people, thus sustaining their oppression. Lastly, Harvard psychologist Gordon Allport (1954) conducted 
pioneering research on the relationship between prejudice and categorical thinking, finding that categorizing people — though natural — has detrimental effects on individuals.

Indeed, these pioneering studies have served as the foundation for much of the research on discrimination and prejudice. However, an ongoing issue that is not widely recognized is that research on racism, discrimination, and prejudice can be thought of in terms of different level of analysis. The following sections describe these four levels of analysis - implicit, subtle, explicit, and institutional—in detail, providing key research findings for each. With respect to understanding how these forms of racism play out for adolescents, our knowledge is clearly uneven, which is reflected in the discussion. Nevertheless, research with adults is also highly relevant to adolescents in terms of understanding the foundational concepts; that is, there is no reason to believe that these four levels of analysis do not also characterize adolescents' racial environments.

\section{Level 1: Implicit Bias and Racism}

Implicit racism refers to unconscious biases and attitudes toward those who are perceived to be from other ethnic or racial groups. It is considered implicit because biases and attitudes are often automatic and occur outside awareness (Zescott, Blair, \& Stone, 2016). These psychological biases and attitudes can be best characterized by implicit prejudice and stereotyping, which can impact an individual's judgment and behavior when interacting with ethnic and racial minorities. Implicit prejudice refers to negative attitudes that people harbor toward racial and ethnic minorities, whereas implicit stereotypes refer to the nonconscious associations that are held about racial and ethnic minorities. Implicit attitudes and stereotypes are often juxtaposed with explicit attitudes and stereotypes (which will be discussed later) in both the 
theoretical and the empirical literature. In returning to the initial example described with Hayes above, we can most readily see implicit racism toward the latter half of the scenario.

Recall that Hayes - the only American Indian student at his high school—made numerous attempts to hang out with a friend he had made on the weekend. Eventually, Hayes's friend told him that his parents had said he could not hang out with Hayes outside school. This is not surprising, as research has demonstrated that implicit biases and stereotypes are produced and maintained through lack of contact with those from other ethnic and racial groups. Given the negative stereotypes expressed toward Hayes by other students, and the lack of interaction students and teachers have with American Indian students, there are likely implicit biases and stereotypes underlying the decision of the friend's parents to prohibit him from hanging out with Hayes. Indeed, implicit prejudice and stereotypes have consistently been demonstrated to explain social inequality among racial and ethnic minorities in various contexts, including education, health care, and organizations. Consequently, the majority of research on implicit biases has been conducted within the realm of social psychology to better inform the study of intergroup processes.

Much of the interest on implicit bias has been spurred by the finding that implicit biases have more explanatory power for discriminatory behavior than explicit biases. That is, implicit biases have strong implications for worse social interactions, as well as for prejudiced behavior. Time and time again, implicit biases have been demonstrated to have significant implications for racial and ethnic minorities above and beyond explicit biases. Implicit biases are especially pervasive in health care and the legal system, and are a key cause of employment discrimination (Zescott et al., 2016). 
Consequently, social psychologists have gone to extensive lengths to develop a formal measure of implicit biases, resulting in the Implicit Association Test (IAT; Greenwald, McGhee, \& Schwartz, 1998). The IAT is a reaction-time-based automated task that is designed to detect individuals' preferences, or biases, that may exist outside their awareness. For example, one version of the IAT purports to detect the degree to which individuals associate the category "White" with positive attributes and the category "Black" with negative attributes. There has been a substantial amount of research conducted with the IAT, with findings suggesting that the unconscious, rather than the conscious, governs much of our discriminatory behavior. More recently, however, there have been findings that contradict this view. Specifically, a metaanalysis found that the IAT does not provide additional insight into discriminatory behavior above and beyond measures of explicit bias (Oswald, Mitchell, Blanton, Jaccard, \& Tetlock, 2013). As implied by these findings, theories of prejudice and methodological approaches are continually developing and may be in need of reform. Additionally, it is important to distinguish implicit racism, which operates outside our awareness, from other forms that are conscious but perhaps unintentional, such as subtle racism.

\section{Level 2: Subtle Racism}

As suggested by its name, subtle racism is considered to be more covert in nature; that is, it is racism in disguise. Additionally, subtle racism is an ambiguous and ill-defined practice, which contributes to its obscurity (Sue et al., 2007). Racism, which was once characterized by an outward display of overt prejudice and discrimination, transformed into something much more difficult to identify and grasp. Certainly, racism has changed in recent years as the belief in ethnic and racial equality has come into direct conflict with the history of racism in the United States. This conflict, characterized by conscious, democratic values such as egalitarianism, 
produced a form of racism that was in alignment with this shift in society. Types of subtle racism that have been discussed in the literature include modern racism, symbolic racism, and aversive racism, all of which are covert and difficult to discern (Sue et al., 2007).

Both modern and symbolic racism are characterized by the rejection of personal prejudice through strict adherence to what are considered traditional values. On the other hand, aversive racism is characterized by conscious adherence to egalitarian values and nonconscious antiminority sentiments. As delineated in the literature, these forms of subtle racism are associated with specific political ideologies. For instance, modern and symbolic racism are closely related to political conservatives, while aversive racism is associated with White liberals. In terms of consciousness, aversive racists are considered the least conscious of their prejudice, followed by modern and symbolic racists, whereas modern and symbolic racists are considered to be more prejudiced than aversive racists.

Indeed, these forms of racism are difficult to discern given their elusive qualities. Undeniably, subtle racism is difficult to pinpoint, measure, and remedy due to its obscure nature. In considering the situation outlined above with Hayes, subtle racism seems to be most evident in his interaction with his teacher. As we recall, Hayes's teacher poses the question, “If you don't live on the reservation, where do you live?" Hayes interprets this interaction as the teacher being well intentioned, though he is clearly unsettled by it. This question, though brief and seemingly not meant to cause harm, conveys the message that Hayes, as an individual, and American Indians, as a group, could not possibly live off reservations and exist in modern societies. Broadly speaking, what Hayes experiences is a microaggression (Sue et al., 2007). More specifically, this interaction could be considered a microinsult, as it is insensitive and demeaning to Hayes’s ethnic and racial identity (Sue et al., 2007). Consistent with the literature on 
microinsults, the subtle snub inherent in the interaction seems to be outside the consciousness of Hayes's teacher, and yet it still communicates a masked insult to Hayes about himself and American Indian peoples.

Racial microaggressions are everyday slights and insults that denigrate individuals with marginalized identities. Racial microaggressions are brief in nature, can be intended or unintended, and convey hostility and negativity to a single person, or even an entire group. Racial microaggressions can occur verbally, behaviorally, or environmentally. According to the theory, microinsults refer to intentional or unintentional subtle snubs that degrade individuals, whereas microinvalidations are behaviors that negate individuals' lived experiences. Lastly, microassaults are subtle but intentional, and are intended to demean individuals. Various themes of microaggressions have been identified — nine, to be exact — all of which include covert assumptions and messages about the person or group to which they are directed (See Sue et al., 2007 for complete list and description). As a result of their invisibility, racial microaggressions confuse and disorient the target (who may have difficulty identifying the experience) and the perpetrator (who may have difficulty believing that they are prejudiced). Research has suggested that experiences with microaggressions have a larger impact on psychological outcomes than overt racism. Finally, it is important to note that the vast majority of psychological research on microaggressions, and subtle racism more generally, has been conducted in the United States, so not much is known about these experiences and associated impacts and correlates in other countries.

\section{Level 3: Explicit Racism}

Contrasted with implicit and subtle racism, explicit racism refers to experiences of blatant discrimination and prejudice. Though it was a commonly held belief that the United States 
became a postracial nation during the Obama presidency, this has largely been demonstrated to be a myth, as experiences with discrimination and prejudice are common for adolescents. Indeed, this is the level of racism that has received the greatest empirical attention with adolescents. Rates of racial and ethnic discrimination have suggested that adolescents are targets of a wide range of discriminatory behavior, including verbal and physical harassment, and low expectations in various areas of functioning (e.g., educational and occupational). Moreover, the perpetrators of these behaviors and attitudes are both peers and adults (Greene, Way, \& Pahl, 2006). The precise frequency of experiencing discrimination varies from study to study, based on factors such source, type, group, and age. But, generally speaking, few studies report less than $50 \%$ of their sample having experienced some form of discrimination in the past month, and it is not uncommon to come across studies finding upwards of a frequency of $90 \%$.

Not only are adolescents targets of discriminatory behavior and prejudicial attitudes but it has also been found that these experiences are associated with adolescent well-being (Benner, 2017). Discrimination has been shown to be related to the mental health of adolescents, wherein adolescents who have experienced greater levels of ethnic and racial discrimination endorse more severe levels of depression, anxiety, stress, and loneliness. Moving beyond mental health, experiences with discrimination and prejudice are also associated with adverse educational outcomes, in which adolescents who experience discrimination by educators are more likely to encounter academic difficulties, while discrimination by peers is associated with socioemotional functioning. Greater levels of discrimination have also been associated with risky behavior among adolescents, such as substance use and other delinquent behavior. Thus, when considering the discriminatory and prejudicial experiences of adolescents, it is critical to consider the source (Benner, 2017). In considering the scenario with Hayes, it is likely, then, that 
the discriminatory remarks made by his peers could impact his social and emotional functioning, while the more subtle comments made by his teacher could influence his academic abilities. Importantly, however, the majority of research on adolescent discrimination has been crosssectional, so there is a need for more longitudinal and experimental studies to truly understand the causal relationship between discrimination and well-being.

Seemingly, the perpetrator or source of discrimination is an important factor in understanding links between discrimination and various areas of functioning. However, it is also important to note that the sources of discrimination may vary across populations. For instance, Black adolescents report greater levels of discrimination over time in which adults are the source of discrimination, whereas non-Puerto Rican Latino/a and Asian American adolescents report greater levels of discrimination in which peers are the source of discrimination in comparison to Puerto Rican adolescents (Green et al., 2006). It has also been demonstrated that, as adolescents experience greater levels of discrimination over time, they also experience greater levels of depression and decreases in self-esteem.

Unlike the research with subtle racism, research on blatant racism has been conducted extensively outside the United States. For example, the International Comparative Study of Ethnocultural Youth was an extensive study of over 8,000 adolescents from 13 countries (Berry, Phinney, Sam, \& Vedder, 2006). One key finding from this project is that perceived discrimination was associated with lower levels of both psychological $(r=-.31)$ and sociocultural $(r=-.30)$ adaptation among immigrant youth, indicating that it is part of the challenge of integrating with society. In general, research conducted around the world has generally pointed to the same conclusion: that adolescents (and adults) from ethnic/racial 
minority backgrounds experience discrimination on a relatively frequent basis, and that these experiences are associated with lower well-being.

Given the high rates of discrimination experienced by adolescents and the established links with various areas of functioning, it is important to explore factors that protect adolescents from adverse outcomes. Seemingly, adolescents who have a sense of pride associated with their ethnic/racial identity do not show associations between discrimination and well-being in the same way as peers who do not have that sense of pride. Other protective factors include people who serve as sources of support for adolescents. Specifically, having positive relationships with family members, friends, mentors, and educators can protect against negative associations with discrimination (Benner, 2017). Considering again the scenario with Hayes, this seems to suggest that strong, supportive relationships with his parents or perhaps friends outside school may serve as a buffer for his experiences with discrimination.

\section{Level 4: Institutional Racism}

Finally, a discussion on racism would not be complete without addressing institutional racism. Institutional racism refers to the merging of history, ideology, policies, and practices that produce and maintain inequalities among ethnic and racial groups. As briefly mentioned at the beginning of this entry, institutional racism is structured to benefit particular groups of people to the detriment of others. In other words, institutional racism designates people outside the dominant group as deserving of differential treatment. Within the United States, the dominant group would be White Americans and, thus, those receiving differential treatment would be ethnic and racial minorities. Given the nature of institutional racism, it often goes unnoticed, as White Americans have become accustomed to such inequalities and inequities to the extent that they are considered the norm for ethnic and racial minorities. Consequently, institutional racism 
is considered unseen or invisible (Lipsitz, 2005). Due to the global supremacy of Whiteness, institutional racism operates in very similar ways across many other parts of the world.

Institutional racism occurs at a broader level, and is enacted through processes, behaviors, and attitudes that inform policies and practices that disadvantage ethnic and racial minorities. Such practices and policies benefit the dominant group when it comes to opportunity structures, such as employment, education, and housing. In contrast, individuals who do hold a dominant identity have differential access to these opportunities. Institutional racism is also embedded in the legal system—including crime, policing, and prisons—as well as in politics and health care. As suggested by these examples, racism is entrenched within these systems, and an individual's ethnic or racial group determines what sort of opportunities — or lack thereof-they will have access to.

Revisiting the scenario with Hayes one last time, we can see institutional racism embedded throughout the example. For instance, Hayes is the only American Indian student at his competitive, private high school. This is interesting, considering that his high school is located in a town that borders a reservation. Surely there are other American Indian adolescents in the area who could attend that high school. Though distance is clearly not a barrier, there appear to be other issues at hand. For example, the requirements for students to be admitted to the school and the tuition fees associated with private high school attendance may limit access to such educational opportunities for students from marginalized backgrounds.

\section{Future Directions}

The primary future directions are twofold. First, there is a great need for researchers, educators, practitioners, and policy makers to be aware of the four different types of racism and how they may shape individuals' experiences. It may be tempting to, for example, note a lack of 
experiences around explicit racism and then conclude that an adolescent is not adversely impacted by the racial context. Simultaneous attention to all four types of racism can both prevent this potentially false interpretation and deepen our understandings of the complexities of racism.

The second recommendation follows from the first: There simply needs to be more research on the different levels of racism, especially among adolescents. As noted, most of the existing research with adolescents focuses on explicit racism. This is obviously important, but there must be attention given to the other levels as well. Social psychologists have extensively studied implicit racism, and counseling and clinical psychologists have studied subtle racism, but neither of these fields tend to include adolescent samples. No area of psychology has been particularly good at conceptualizing and measuring institutional racism, as it falls outside the traditional individual focus of psychology. This needs to change if we want to productively understand how racism at all levels impacts adolescent experiences. 


\section{References}

Allport, G. (1954). The nature of prejudice. Reading, MA: Addison-Wesley.

Batz, D., \& Braly, K. (1933). Racial stereotypes of one hundred college students. Journal of Abnormal and Social Psychology, 28, 280-290.

Benner, A. (2017). The toll of racial/ethnic discrimination on adolescents' adjustment. Child Development Perspectives. doi:10.1111/cdep.12241

Berry, J. W., Phinney, J. S., Sam, D. L., \& Vedder, P. (2006). Immigrant youth: Acculturation, identity, and adaptation. Applied psychology, 55, 303-332.

Blumenbach, J. F. (1795). De generis humani varietate native (3rd ed.) [On the natural variety of humankind]. Gottingae: Vandenhoek and Ruprecht.

Cole, N. L. (2017, July 24). The definition of racism. Retrieved from https://www.thoughtco. com/racism-definition-3026511

Greene, M. L., Way, N., \& Pahl, K. (2006). Trajectories of perceived adult and peer discrimination among Black, Latino, and Asian American adolescents: Patterns and psychological correlates. Developmental Psychology, 42, 218-238.

Greenwald, A. G., McGhee, D. E., \& Schwartz, J. L. K. (1998). Measuring individual differences in implicit cognition: The Implicit Association Test. Journal of Personality and Social Psychology, 74, 1464-1480.

Herrnstein, R. J., \& Murray, C. (1994). The bell curve: Intelligence and class structure in American life. New York, NY: Free Press.

Katz, D., \& Braly, K. (1933). Racial stereotypes of one hundred college students. The Journal of Abnormal and Social Psychology, 28, 280-290. 
Kite, M. E., \& Whitley, B. E. (2016). Psychology of prejudice and discrimination ( $3^{\text {rd }}$ ed.). Abingdon, UK: Routledge.

Lipsitz, G. (2005). The possessive investment in whiteness. In P. S. Rothenberg (Eds.), White privilege: Essential readings on the other side of racism (pp. 1-25). Basingstoke, UK: Worth Publishers.

Miles, R. (1989). Racism. London, UK: Routledge.

Myrdal, G. (1944). An American dilemma: The Negro problem and modern democracy. Piscataway, NJ: Transaction Publishers.

Oswald, F. L., Mitchell, G., Blanton, H., \& Jaccard, J., \& Tetlock, P. E. (2013). Predicting ethnic and racial discrimination: A meta-analysis of IAT criterion studies. Journal of Personality and Social Psychology, 105, 171-192.

Smedley, A., \& Smedley, B. D. (2005). Race as biology is fiction, racism as a social problem is real: Anthropological and historical perspectives on the social. American Psychologist, $60,16-26$.

Sue, D. W., Capodilupo, C. M., Torino, G. C., Bucceri, J. M., Holder, A. M. B., Nadal, K. L., \& Esquilin, M. (2007). Racial microaggressions in everyday life: Implications for clinical practice. American Psychologist, 62, 271-286.

Zescott, C. A., Blair, I. V., \& Stone, J. (2016). Examining the presence, consequences, and reduction of implicit bias in health care: A narrative review. Group Processes \& Intergroup Relations, 19, 528-542. 


\section{Further Readings}

Pascoe, E. A., \& Smart Richman, L. (2009). Perceived discrimination and health: a meta-analytic review. Psychological Bulletin, 135(4), 531.

Sue, D. W., Capodilupo, C. M., Torino, G. C., Bucceri, J. M., Holder, A. M. B., Nadal, K. L., \& Esquilin, M. (2007). Racial microaggressions in everyday life: Implications for clinical practice. American Psychologist, 62, 271-286.

Tatum, B. D. (2017). Why are all the Black kids sitting together in the cafeteria? And other conversations about race (Revised and updated). New York: Basic Books. 


\section{Biographies}

Jillian Fish (MS, State University of New York at Buffalo, 2014) is a doctoral student in the Counseling Psychology Program in the Department of Psychology at the University of Minnesota, Twin Cities, USA, and a recipient of the Ford Foundation Predoctoral Fellowship. Her research interests include transforming social institutions, such as colleges and universities, to be more inclusive and equitable for American Indian peoples. She complements her research with community engagement, volunteer work with American Indian youth, and activism.

Moin Syed (PhD, University of California, Santa Cruz, 2009) is an Associate Professor of Psychology at the University of Minnesota, Twin Cities, USA. His research is broadly concerned with identity and personality development among ethnically and culturally diverse adolescents and emerging adults. He is a coeditor of the Oxford Handbook of Identity Development (with K. C. McLean, 2015, Oxford University Press) and editor of Emerging Adulthood, the official journal of the Society for the Study of Emerging Adulthood. 